\title{
APPLICATION OF EXPERT SYSTEMS OR DECISION- MAKING SYSTEMS IN THE FIELD OF EDUCATION
}

\author{
Biju Theruvil Sayed ${ }^{1}$ \\ ${ }^{1}$ Department of Computer Science, College of Arts \& Applied Sciences, Dhofar University, P.O. Box 2509, P. Code 211, Salalah, \\ Sultanate of Oman \\ Assistant Professor, Department of Computer Science, College of Arts \& Applied Sciences, Dhofar University, P.O. Box 2509, P. \\ Code 211, Salalah, Sultanate of Oman
}

\begin{abstract}
Expert system (ES) is a branch of artificial intelligence (AI) that is used to manage different problems by making use of interactive computer-based decisionmaking process. It uses both factual information and heuristics to resolve the complicated decision-making issues in a specific domain. The architecture of the expert system was analyzed and found that it includes several parts such as user interface, knowledge base, working memory, inference engine, explanation system, system engineer, and knowledge engineer, user, and expert system shell in which each part of the architecture of an expert system is based on different functionary that helps it to make an adequate decision by analyzing complex situations. The research aims to analyze the application of expert systems or decision-making systems in the field of education and found that it is used for different purposes such as assessing teacher performance, providing guidance to the students regarding their career, and providing quality learning to students with disabilities. It is also used to help the students to make rightful career decisions and become efficient professionals after completing their studies
\end{abstract}

Keywords: expert system; education; student, knowledge; system engineer

\section{Introduction}

Expert system (ES) is a branch of artificial intelligence (AI) that is used to manage different problems by making use of interactive computer-based decision-making process. It uses both factual information and heuristics to resolve the complicated decision-making issues in a specific domain (Mohammed et al., 2019). It is a computer program that manipulates reasoning and learning to resolve problems. It includes subduing the problems into narrow problem areas by making use of extensive sources of knowledge and human expert assistance (Bolloju et al., 2012). For example, Computer-Aided Instruction (CAI) is an Expert System based application that uses heuristics to resolve complex issues in the education field. ES is included in games, colorful graphs, puzzles, and sounds to increase student attentiveness from the beginning to the end of the session. The use of an expert system is highly beneficial as it helps in improving decision quality and reducing expenses related to consulting with experts for resolving the problems. ES helps in gathering scarce expertise and utilizes them efficiently to solve complicated problems. It also provides a consistent solution to the problems that are reoccurring in nature and helps in maintaining a significant level of information to acquire fast and accurate resolutions (Ismailet al., 2009). ES provides a logical explanation behind reaching a decision and resolves complex issues without getting emotional. Expert systems are applied in different fields such as transportation, medical, education, and others to support an easy decision-making process. For example, in transportation, ES is used maintain flexible pavement and resolve the problems that arise in different stages of construction such as material handling, hauling, stockpiling, and others (Ismail et al., 2009). In the medical field, ES is used in the form of a Multi-Criteria Decision Making (MCDM) process to assess the value of healthcare studies. Additionally, Expert System based MYCIN is used to identify different bacteria that cause acute infections by using backward chaining (Mardani et al., 2019). On the other hand, in the case of education, ES is used for different purposes such as intelligent tutoring systems, human tutoring, and answer based tutoring purposes. AI-based ES can be efficiently used in online and distance learning programs that will help in spreading learning and knowledge-based activities among large masses (Goksel \& Bozkurt, 2019). However, the major limitation with ES application is that it does not provide creative responses and gets impacted by errors in the knowledge sources. The maintenance cost of ES is high and requires extensive expert and knowledge sources to analyze the issue and provide answers. The current research focuses on analyzing the application of Expert systems or DecisionMaking systems in the field of education and discusses the need of integrating Expert Systems in education. The facts related to the architecture of expert systems and their application have also been included in the research.

\section{Statement of the Problem}

An expert system is AI design-based software that is used to offer a solution to complex problems so that the need to consult with experts gets eliminated. The system acts on behalf of the human knowledge experts, provides answers and 
explanations that facilitates the decision-making process of the individual. However, the major issue with the application of an expert system is that it requires a significant amount of time to analyze the different knowledge sources and provide answers for complex issues. The decision that is made by using ES is based on an analyzing system and inference set of rules in the system It cannot make creative or innovative responses like human experts under atypical conditions. Another major issue with ES is high implementation cost which creates a financial burden for the small enterprises to implement the process. Moreover, the maintenance and upgrading cost associated with ES is also high that limits its application in different fields. The task of codifying knowledge is highly complicated which makes it difficult for the experts to explain the rationale and reasoning behind the knowledge engineering practices in ES. It leads to the creation of complicated ES and stringent inference rules that consumes a lot of time to provide a solution to the queries.

The solutions that are provided by ES are not error-free. If there is an error in the knowledge base, it leads to the provision of wrong solutions that hampers individual and business working processes. It has more bugs in its programs that are difficult to maintain and include high costs for development. It requires ground verification for implementation and applies no common sense to provide solutions. It is not efficient in complex automation processes and possesses legal and ethical consideration on implementation. Due to certain challenges such as not adaptable to altering environments, less flexibility, and manual updating requirements, the use of an expert system gets restricted in the fields of education. Therefore, to increase the applicability of ES, the inference rules of ES must be simplified and the computational practices must be made easy for use by the skilled and unskilled individual.

\section{State of the Art Technology}

Expert systems are computer software-based systems that make use of extensive knowledge bases to provide solutions like expert human resources. The use of ES has increased over years and significantly used in individual and business processes to make numerous decisions such as carrying out a medical diagnosis for individual health or buy a laptop to meet business needs (Alshare et al., 2019). The use of ES by firm and individual is guided by several factors such as familiarity with ES, perceived relevance, top management support, expert system domain, and environment of the firm. The external variables such as management support and perceived relevance lay a direct impact on the expectancy, quality, and reliability of the expert system ad increase its acceptability among the users (Alshare et al., 2019).

An expert system is related to system thinking that helps in enhancing the education and learning level of the students. The main reason behind the high efficacy of system-based thinking (STEM) education is that it is based on higher-order thinking skills. It includes critical thinking and creative thinking so that the analytical abilities of the students are developed. STEM content retains the maximum concentration of the students to the course and helps in developing problemsolving abilities among the students. However, the adoption of the system thinking way is no way as it does not comes naturally to the students. As a result, most of the students tend to think that the system thinking process is static and isolated (Supriyanto et al., 2019).

An expert system is also implemented in the career guidance of the students so that they become able professionals after acquiring the educational qualifications. Career selection is one of the most difficult tasks for the students after completing secondary education and moving towards the attainment of higher or professional education. Therefore, an expert system is used to guide the students to make a rightful decision so that it will be beneficial in their career development and individual growth process in the future. An expert-based system helps the student to evaluate independent learning, independent performance, and choose competencies so that they can make career-related decisions (Supriyanto et al., 2019).

An expert system is also used to build a knowledge-based network system as it makes efficient use of adaptive rulebased applications. It includes developing two types of nodes which are question nodes and action nodes. The question node is based on input connections whose values change as per a profitable enquire and search. Each input-connection with twin output- connections, every over as connects according to another question node then action node. A query node carries a relevant query then a corresponding answer-key. During a thought process, condition a question node is activated via a message, the question is evaluated, or the answer cost will lead according to the subsequent activation (Goel \& Agarwal, 2019). An action node can also incorporate some or greater input- connections, every weighted, whose values change based on whether or not person remarks are superb or negative. An assignment node consists of one then more actions, to activate messages that are sent from question nodes. Also, such a knowledge- node-network incorporates a preliminary body of knowledge (a group over query nodes and action nodes with remarkable connections). Upon interaction including ethnic users, its preliminary physique of knowledge might also show insufficient within the context about an altering problem. The dictation adapts to these changes through the modification of existing advantage nodes or the introduction of new knowledge nodes (Dev, 2020). Thus, it can be said that an expert system is efficiently used in different applications depending on the different applications such as fuzzy logic, machine learning, and others associated with it.

\section{Related Works}

An expert system is a computer software system that makes use of science, technology, and thinking techniques to resolve the problem and help the user to make decisions. The use of an expert system in the education system varies based on the knowledge of the
ISSN (Print): 2204-0595 ISSN (Online): 2203-1731 
researcher and problem domain. Therefore, the application of the expert system in the education field can be exercised by considering input, process, output, and outcome. The expert system applicability in the education industry is related to the determination of student features, efficacy analysis, and assessment of e-learning efficacy. It also includes determining the performance of digital libraries, technical education, and makes predictions related to student performance (Tan et al., 2016). The character-based assessment, education evaluation, remedial system, and lesson plan formulation is also carried out with the help of an expert system. The educational, professional skills counseling and career guidance services are also provided with the help of expert system based education processes (El Haji et al., 2014).

Innovation models are used to enhance decision making in the field of education by increasing the thinking and analyzing capabilities of the individuals. For example, the DoubleFlanked Conceptual Model For Measuring Innovation (DFCMI) is used as an efficient innovation-based model to resolve the issues that are related to knowledge sharing in the educational organization [Figure 1 near here].

The model includes the Community of Practice (CoP) and SECI Model along with technology and innovation so that there is an achievement of social cohesiveness. CoP emphasizes the use of interactive communication techniques such as easy language, jokes, and problem vision to manage the students. On the other hand, the SECI model focuses on the use of technology-based applications to establish interactions with students. It includes online interaction through webinars and videos to promote a virtual learning environment. Thus, by making efficient use of both techniques quality education could be provided to students through personal as well as online interactions (Mustapha et al., 2017). Expert system includes fuzzy logic applications that help in implementing human knowledge to with imprecise. It helps in the verification of the ambiguous and uncertain data and provides reliable and relevant information to the user. For example, fuzzy logic is used in the education industry to assess the teaching methodology of the teachers. The learning effectiveness of the students can also be analyzed by making use of a fuzzy logic-based expert system (Khan et al., 2011). It includes the use of a fuzzy set approach to analyze the studentcentered learning process that is studying in educational organizations. For analyzing the efficacy of the teacher, the fuzzy logic includes certain features such as proficiency of teaching, personal interest in teaching, and presentation \& communications skill. It also includes other features such as response to student queries, speaking style \& body language, language command, content knowledge, and lecture preparation. When these aspects of the teachers were compared with the fuzzy logic scale, the effectiveness of the teacher was identified concerning student learning (Khan et al., 2011).
Enhance Quality Academic Skills (EQAS) system can also be used to increase the efficacy of the students by mapping every subject and curriculum. The EQAS system includes different assessment processes such as Individual Measurable Evaluation \& Assessments and Group Wise Measurable Results of Evaluation \& Assessments that help in acquiring reliable information about the student performance and learning status. It helps in identifying the strengths and weaknesses of the students and develop their knowledge and skill to optimized levels (Sayed et al., 2019).

An expert system is used to select standard content to provide quality education to the students. It includes the implementation of a Content Personalization service (CP) so that resource and device properties are taken into account to provide quality virtual education to students with disabilities. The module is classified into different parts such as web service layer, common translator, decision-maker, profile management, and data access object layer to substitute the rules-based engine and includes an expert-based system for quality learning (De La Cámara et al., 2009). Thus, it can be said that expert systems are efficient AI-based tools that are used in the field of education to make decisions, analyze performance, and bring improvement in the learning capacities of the students.

\section{Architecture of Expert System}

The architecture of the expert system is based on different components such as user interface, knowledge base, working memory, inference engine, explanation system, system engineer, knowledge engineer, user, and expert system shell

\section{[Figure 2 near here].}

The knowledge base of the expert system is known as the warehouse that is filled with specific heuristics and rules. These knowledge-based databases are used for the productions of answers and resolutions for problems. It is known as the learning that is required to acquire understanding about the problem and resolve it by formulating adequate logical responses. Working memory describes the prevailing running issue and records instantaneous output against it. It includes recording an intermediate hypothesis in a planned manner by focusing on the agenda. It results in the procurement of a solution that is based on logical explanations and justifications. The inference engine is the center component of the expert system that manages the entire structure and delivers different methodologies for the analysis and interpretation purposes (Shen et al., 2010). The inference system includes the use of a forwarding and backward chaining system that helps in extracting information from the databases. The forward-chaining helps in collecting data and providing absolute solutions. On the other hand, backward chaining is used to find the desired solutions and support the solution.

The explanation system is responsible for authenticating and verifying the application of the expert system by focusing on Why, How, What,

ISSN (Print): 2204-0595
ISSN (Online): 2203-1731 
Where, When, Who questions. It provides a solution by showing a specific path so that the user reaches a definite finale. Most of the expert systems use explanation facilities to derive recommendations. As a result, the user can understand how ES concludes by making use of certain alternatives and rejecting others. It includes the use of data input, system goals, and decision rules to reach a specific conclusion (Prasad et al., 1996).

The user interface is the system through which queries are inserted by the users by making use of Natural Language Processing, menus, and graphics. The system acts as an intermediary tool that helps in establishing interactions between the user and the interface system. It helps in simplifying the ES usability process for the administrators and users by making use of AI-based technology. As a result, the computers read the instructions or queries that are provided by the human and provide them apt responses by analyzing the knowledge-based facts and presenting them through graphics and graphical presentations (Bolloju et al., 2012). The knowledge engineer is the fundamental part of the architecture of the expert system that designs the system to acquire responses for specific domain issues by making use of the ES shell. The knowledge engineer aligns the knowledge base, user interface, and inference engine so that they act as the foundational base for the ES decision-making process (Tripathi, 2011). It includes the use of several knowledge management tools such as trees, semantic networks, frames, scripts, and production rules.

The system engineer is responsible for designing the declarative format of the knowledge base so that there is the development of an efficient inference engine. It helps in extracting information from the knowledge database and providing solutions like human experts (Omran et al., 2006). Users are the non-experts in confusion and seeking solutions for complex problems faced by them.

The expert system shell includes specialized software that helps in developing a knowledge-based environment. It is composed of different components such as user interface, reasoning capacity, workplace, and others that help in building and supporting solutions. The shell includes the use of a predefined methodology that helps in designing diversified applications and configuring them through interference engine and explanation facility. Different shells such as C Language Integrated Production System (CLIPS), OPS5, ART, and Eclipse are used to define the expert system (Liao, 2005).

\section{Applications of Expert System}

An expert system can be defined as an interactive computeraided decision-making process that makes use of facts and heuristics to resolve complicated issues. The key components of an expert system are the Knowledge-Based System (KBS), rule-based system, artificial neural network (ANN), fuzzy expert system, modeling, and Case-based reasoning (CBR) (Reffat \& Harkness, 2001). Due to the presence of different user-based components, expert systems are used in different fields and industries such as construction, transportation, automobile, healthcare, education, supply chain, and others. For example, the expert system is used for weather forecasting as the forecasting processes make use of several rules to predict the weather conditions. It includes analyzing rules based on humidity, temperature, jet stream, and wind so that potential weather patterns are determined (Reffat \& Harkness, 2001).

The expert system is also used in logistics management processes that are related to natural disaster management. The ES based software helps the technician to make decisions related to the placement of equipment to provide relief resources. Thus, ES based application is used to improve the disaster management process after hurricane, earthquake, forest fire around the world. ES is also used in war-simulation programming specifically to ascertain the human causalities and armory logistics at the time of war. It helps the governing body to make a decision related to the adoption of the best confrontation program for the war simulation process. ES has used in credit card and loan processing processes that help in determining the credit risks of the lenders (Ramadan \& AlSaleh, 2013).

An expert system is used in the healthcare sector to detect medical errors by developing a hierarchical structure of CLIPS. It helps in checking the patient input and consistency as per the specified limits and validate the outcomes with several expert views. As a result, any fear associated with wrong medication is eliminated and up-dated information is provided to the medical staff (Ramadan \& Al-Saleh, 2013). ES is used to develop Dilated Cardiomyopathy that helps in diagnosing disease symptoms among the patients. It includes the use of clips language, decision tree, and rule-based application so that certainty factor (cf) of the patient is acquired (Bahrami et al., 2014). an expert system is used to provide treatment to the patients that are suffering from nephrolithiasis by developing a knowledge base consisting of three sections (actions, rules, and statements) (Mirmozaffari, 2019).

An expert system is used in the automobile industry to determine errors in the functioning of vehicles and diagnose car failure. ES contains a different set of rules that helps in discovering different types of errors and failures that makes it easier for the driver to resolve the issue. For example, ES oriented Knowledge-Based Systems (KBS) has been introduced that help in diagnosing car failure. On the other hand, an expert system is also used in the agriculture industry to increase agriculture productivity and ensure food security. For example, an expert system based on Integrated Swine Manure Management (ISMM) was developed in Canada to resolve the issues related to swine manure management. The model was based on Visual Basic programming that helped in reducing greenhouse gas and promoting environmental, agronomic, and social health. Expert system was also used to develop a model 
through which the disease management could take place in finger millets by the cultivators. The model was on the use of both factors that helped in acquiring information about a new type of disease found in finger millet farms (Shokouhyar et al., 2018).

Expert system-based fuzzy logic is used in the supply chain industry to assess supplier capabilities and develop the existing supplier base. By applying fuzzy logic processors of the expert system, there is finding viable new suppliers that help in achieving operational benefits and reducing cycle time cost. On the other hand, the application of a fuzzy logic-based expert system helps the insurance specialists to make decisions about individual life insurance cases. The expert system helps in analyzing the health status of the individuals and proposes the best policies for them as per the client's suitable premium ranges (Shokouhyar et al., 2018). Thus, it can be said the expert system is highly efficient and used in different fields because of its unique feature that helps in reducing cost and enhancing the decision quality of the individuals.

\section{Why is the Expert System Required in Education?}

AI-based Expert systems are increasingly used in the education field as it provides extensive teaching tools to the educators and converts the traditional educational practices intelligent teaching systems (Jabbar \& Khan, 2015). ES based teaching tools possess matchless characteristics that allow the user to ask any question in Why, How, What, Where, When, Who format. As a result, it increases the ES user's knowledge and learning provision abilities. In the education field, initially, ES was developed to reduce the scarcity of teachers in different regions around the world. The ES was created to augment the availability of knowledge to several individuals that are acquiring specialization in engineering, mathematics, and earth sciences through distance learning courses (Nwigbo Stella \& Chuks, 2011).

By introducing significant modifications in ES with the growth of technological advancements, the ES helps in discovering lost expertise. It will help in modeling better professionals without making use of human professionals. As a result, a strong team of mentors and experts could be developed to meet the skilled educational personnel gaps in different learning sectors (Sakala et al., 2010). For example, educational advisor system has been developed by making use of a web-based fuzzy expert system that helps in analyzing student behavior and makes them student education advisor (Goodarzi \& Rafe, 2012). ES based mobile intelligent tutor system has been developed that helps in increasing the learning of the users. It is based on three vital processes such as pre-test, learning concept, and post-test so that the user acquires extensive subject knowledge. In the mobile intelligent tutor system, an expert simulator and its knowledge base are used as a server that enables thousands of students to learn and gain knowledge in an integrated way simultaneously (Ghadirli \& Rastgarpour, 2013).
An Iterative Expert System for Track and Field Teaching was developed in the year 2013 to promote quality education among large student groups. The ES based Track and Field Teaching program are based on an e-learning concept that helps in creating the base design structure and providing learning about different subjects through teacher networking. Thus, by using this program and internet connectivity, the user can access large teacher communities and students around the world (Ho \& Chang, 2013). An Expert System for Higher Education was developed in the year 2014 to enhance the education system in Iran. The system is used by the managers of the Ministry of Sciences, Researches and Technology to make decisions related to quantitative development of higher education by considering structural space, the strength of faculty members, and university features (Arya et al., 2014). A web-based Semantic Expert System was also developed that allowed knowledge experts and engineers to define knowledge without making any use of programming languages and artificial intelligence mechanisms (Nofal \& Fouad, 2014).

An expert system has expanded its application in the education field with the inclusion of different technologies such as microcomputer systems, web-based systems, agent-based expert system, and others. For example, the web-based system provides an adequate platform for self-study and an alternative option against private tutoring as the user acquires relevant information from different web-based sources. It also includes the use of hybrid-based technique, Java technology, and fuzzy logic technique so that each user learns as per his/her pace of learning (Fisseha, 2011). It also helps in monitoring the progress of the students and enhances the competencies of the learner's in different fields such as computer science, computer animation, engineering, language, and business study. ES provides a guide to design $2 \mathrm{D}$ and $3 \mathrm{D}$ modeling packages that help in developing efficient tools to teach the subjects such as mathematics (Lucy et al., 2010).

An expert system has led to the development of the Adaptive Educational Programme Tool (ADEPT) that helps in meeting the learning needs of the students [Figure 3 near here].

The ADEPT scheme is based on two decision making blocks that makes the use of an expert system based on fuzzy logic applications. The scheme recommends the best study material by analyzing the learning abilities of the student. Firstly, the system modifies the study material as per the student's needs in the first place and secondly, it modifies the accessed materials to suit the learning of the students. It also recommends study materials and provides a continuous knowledge base to the learner. Knowledge Management Credit Transfer System (KMCTS) has also been introduced to address credit transfer issues by the higher education organization. KMCTS is based on the listing process in which the credentials of the students are distributed in different columns that are listed as knowledge gained, skills obtained, competencies achieved, and other specific components. It is executed by

ISSN (Print): 2204-0595 ISSN (Online): 2203-1731 
making use of mapped rubrics against institution courses. It helps the student to acquire relevant information about the pending courses and attest learning outcomes by fast-tracking the learning processes (Sayed et al., 2019). Thus, it can be said that the expert system is extensively used in the education industry to increase the learning abilities of the students.

\section{Comparative Analysis}

While establishing a comparison between the conventional and expert systems based on knowledge, it was found that in the conventional system, the knowledge and processing units are mixed and used as a combined unit. On the other hand, in the case of an expert system, the knowledge and processing units are used separately as two different components. While considering the error section of both the systems, in the conventional system, there is no scope of making an error in the system unless there is an error in the programming (Syamsunur et al., 2011). On the contrary, the expert system has the possibility of making errors. Considering the operational aspects of both the systems, the conventional system is fully operational only when the entire system is fully developed, while in the case of the expert system, it is an ongoing process that can be launched with a small set of rules and later on updated with an additional set of rules. Focusing on the application process, in the conventional system, there is the implementation of step by step process. All the processes are based on fixed algorithms, while in the case of an expert system it is based on a logical and heuristic application process. Considering the applicability aspect, the conventional system requires full information for the execution process and the expert system can be applicable even with insufficient information (Syamsunur et al., 2011).

While establishing a comparison between the human and expert system, it was found that the human expert tends to be perishable while an artificial expert is permanent. The human expert is difficult to transfer while the expert system is transferable. In the case of a human expert, it is difficult to document the interactions or the knowledge/learning/process used to facilitate the decision-making process, while in the case of an expert system, it is easy to document the entire process of decision making right from analyzing the knowledge base to reaching to the end solution process. The solutions that are given by the human expert are often unpredictable and based on the creative thinking process. On the other hand, in the case of an expert system, the provision of a solution is consistent and based on logical reasoning. The attainment of resolution from the human expert is highly expensive as it includes soaring consultation charges, while in the case of expert system, the cost of attainment of resolution is low as it is known as a cost-effective system (Mosa et al., 2011).

\section{Conclusion}

As per the above-discussed facts, it can be said that expert systems are AI-based computer software application that is used to help individual and firm to make decisions when facing complex challenges. The use of an expert system is found in different sectors such as transportation, healthcare, education, automobile, and others as it includes different applications such as fuzzy logic and machine learning to make proper decisions. The study examined the role of the expert system in the education sector and found that it is used for different purposes such as assessing teacher performance, providing guidance to the students regarding their career, and providing quality learning to students with disabilities. The facts related to the architecture of the expert system were analyzed and found that it includes several parts such as user interface, knowledge base, working memory, inference engine, explanation system, system engineer, and knowledge engineer, user, and expert system shell. Each part of the architecture of an expert system is based on a different functionary that helps it to make an adequate decision by analyzing complex situations. The study examined that expert system includes the use of hybrid-based technique, Java technology, and fuzzy logic technique so that each user learns as per his/her pace of learning. Thus, it can be said that research will be highly beneficial to the students, educators, and educational organizations so that the skills and abilities of the learners are enhanced. It helps the students to make rightful career decisions and become efficient professionals after completing their studies.

\section{Acknowledgements}

\section{References}

[1]. Alshare, K. A., Alomari, M. K., Lane, P. L., \& Freeze, R. D. (2019). Development and determinants of end-user intention: Usage of expert systems. Journal of Systems and Information Technology, 21(2), 166185. https://doi.org/10.1108/jsit-08-2018-

\section{8}

[2]. Arya, S. H., Abolghasemi, M., Ahmadvand, A. M., \& Omran, E. S. (2014). Designing and implementing the higher education development fuzzy expert system in iran. Journal of Mathematics and Computer Science. 08. 163-179. 10.22436/jmcs.08.02.07.

[3]. Bahrami, A., Roozitalab, N., Jafari, S., \& Bahrami, A. (2014). An expert system for diagnosing dilated cardiomyopathy. International Journal of Engineering Science Invention, 3(3), 38-42.

[4]. Bolloju; N., Schneider, C., and Sugumaran, V. (2012). A knowledge-based system for improving the consistency between object models and use case narratives. Expert Systems with Applications, 39(10), 9398-9410 https://doi.org/10.1016/j.eswa.2012.02.126

[5]. De La Cámara, S. P., Soler, E. R., del Viso Torre, A. F., de 
Prada, E. V., \& Sánchez, C. R. (2009). Expert System for Educational Content Selection Based on Standards. In AIED 2009: 14 th International Conference on Artificial Intelligence in Education Workshops Proceedings (p. 23).

[6]. Dev, U. (2020). Re-Engineering Expert System Powered By Machine Learning. Cosmos Journal of Engineering \& Technology, 10(1), 16-20.

[7]. El H., Essaid, A. A., \& Mohamed E,1 i. (2014). Expert system design for educational and vocational guidance, using a multi-agent system. International Conference on Multimedia Computing and Systems -Proceedings.

1018-1024. 10.1109/ICMCS.2014.6911256.

[8]. Fisseha, M. (2011). The role of information communication technologies in education: Review article with emphasis on the computer and the internet. Ethiopian journal of education and science. $6(2)$.

[9]. Ghadirli, H. M., \& Rastgarpour, M. (2013). An adaptive and intelligent tutor by expert systems for mobile devices. International Journal of Managing Public Sector Information and Communication Technologies. 3. 10.5121/ijmpict.2012.3102.

[10]. Goel, A., \& Agarwal, E. (2019). Assessing Innovation in Teacher Education. Globus Journal of Progressive Education, 9(2); 50-52.

[11]. Goksel, N., \& Bozkurt, A. (2019). Artificial intelligence in education: Current insights and future perspectives. In Handbook of Research on Learning in the Age of Transhumanism (pp. 224236). IGI Global.

[12]. Goodarzi, M. H., \& Rafe, V. (2012). Educational advisor system implemented by web-based fuzzy expert systems. Journal of Software Engineering and Applications. 05. 10.4236/jsea.2012.57058.

[13]. Ho, H. M., \& Chang, H. (2013). An iterative expert system for track and field teaching research in the long jump. International Journal of e-Education, eBusiness, e-Management and e-Learning, 3(3), 187. 10.7763/IJEEEE.2013.V3.220.

[14]. Ismail, N., Ismail, A., and Atiq, R. (2009). An overview of expert systems in pavement management. European Journal of Scientific Research, 30(1), 99-111

[15]. Jabbar, H. K., \& Khan, R. Z. (2015, March). Survey on development of expert system in the areas of Medical, Education, Automobile and Agriculture. In 2015 2nd International Conference on Computing for Sustainable Global Development (INDIACom) (pp. 776-780). IEEE.

[16]. Khan, A. R., Amin, H. U., \& Rehman, Z. U. (2011). Application of expert system with fuzzy logic in teachers 'performance evaluation. International
Journal of Advanced Computer Science and Applications - IJACSA. 2. 51-57. 10.14569/IJACSA.2011.020210.

[17]. Liao, S.-H. (2005). Expert system methodologies and applications - a decade review from 1995 to 2004. Expert Systems with Applications, 28(1), 93 103. 10.1016/j.eswa.2004.08.003.

[18]. Lucy, C. S., Obert, M. \& Lemias, Z. (2010). The use of expert systems has improved students learning in Zimbabwe. Journal of sustainable development in Africa. 12(3). Pp 1 - 13

[19]. Mardani, A., Hooker, R., Ozkul, S., Yifan, S., Nilashi, M., Sabzi, H. Z., \& Fei, G. C. (2019). Application of Decision Making and Fuzzy Sets Theory to Evaluate the Healthcare and Medical Problems: A Review of Three Decades of Research with Recent Developments. Expert Systems with Applications. 137. 10.1016/j.eswa.2019.07.002.

[20]. Mirmozaffari, M. (2019). Presenting a Medical Expert System for Diagnosis and Treatment of Nephrolithiasis. European Journal of Medical and Health Sciences. 1. 10.24018/ejmed.2019.1.1.20. .

[21]. Mohammed, A., Ambak, K., Mosa, A., \& Syamsunur, D. (2019). Expert system in engineering transportation: a review. Journal of Engineering Science and Technology, 14(1), 229252.

http://jestec.taylors.edu.my/Vol\%2014\%20iss ue\%201\%20February\%202019/14_1_17.pdf

[22]. Mosa, A., Rahmat, R., Raihantaha, M., \& Ismail, A. (2011). Classification of construction problems in rigid highway pavements. Australian Journal of Basic and Applied Sciences, 5(3), 378-395

[23]. Mustapha, S. S., Sayed, B., \& Mohamad, R. (2017). Measuring process innovation on double-flanked conceptual model for knowledge sharing on online learning environment. Journal of Theoretical and Applied Information Technology, 95(7), 14991509.

[24]. Nofal, M., \& Fouad, K. M. (2014). Developing web-based semantic expert systems. International Journal of Computer Science Issues (IJCSI), 11(1), 103.

[25]. Nwigbo, S., \& Madhu, B.K. (2011). Expert system: a catalyst in educational development in Nigeria. IOSR Journal of Mobile Computing \& Application (IOSR-JMCA), 3(2), 8-11.

[26]. Omran, M.G.H., Engelbrecht, A.P., \& Salman, A. (2006). Using the ring neighborhood topology with self-adaptive differential evolution. Advances in Natural Computation, 976-979. 10.1007/11881070_129.

[27]. Prasad, B.N., Finkelstein, S.M., \& Hertz, M.I. 
(1996). An expert system for diagnosis and therapy in lung transplantation. Computers in Biology and Medicine, 26(6), 477-488. https://doi.org/10.1016/S00104825(96)00030-3.

[28]. Ramadan, M., \& Al-Saleh, K. (2013). Development of an expert system for reducing medical errors. International Journal of Software Engineering \& Applications, 4(6), 29. 10.5121/ijsea.2013.4603.

[29]. Reffat, R.M., \& Harkness, E.L. (2001). Expert system for environmental quality evaluation. Journal of Performance of Constructed Facilities, 15(3), 109-114. 10.1061/(ASCE)08873828(2001)15:3(109).

[30]. Sakala, L. C., Muzurura, O., \& Zivanai, L. (2010). The use of expert systems has improved students learning in zimbabwe. Journal of Sustainable Development in Africa, 12(3), 1-13.

[31]. Sayed, B., Mushikhi, K., \& Chaudhry, S. (2019). A Pragmatic Prototype to Enhance The Quality PreUniversity Level Skills Towards Further Development of Human and Knowledge Attributes in the Region. Procedia Computer Science, 154, 824-831. https://doi.org/10.1016/j.procs.2019.06.073.

[32]. Sayed, B. T., Al Mushikhi, K. M., \& Dhanasekaran, B. (2019). Knowledge Based Information System to Manage Transfer of Credits in An Outcome Based Higher Educational Setting. Procedia Computer Science, 154, 26-32. https://doi.org/10.1016/j.procs.2019.06.006.

[33]. Shen, W., Hao, Q., Mak, H., Neelamkavil, J., Xie, H., Dickinson, J., Thomas, R., Pardasani, A., \& Xue, H. (2010). Systems integration and collaboration in architecture, engineering, construction, and facilities management: A review. Advanced Engineering Informatics, 24(2), 196-207. https://doi.org/10.1016/j.aei.2009.09.001.

[34]. Shokouhyar, S., Seifhashemi, S., Siadat, H., \& Ahmadi, M. M. (2018). Implementing a fuzzy expert system for ensuring information technology supply chain. Expert Systems, 36(1), e12339. 10.1111/exsy.12339.

[35]. Supriyanto, G., Widiaty, I., Abdullah, A. G., \& Yustiana, Y. R. (2019, December). Application expert system career guidance for students. In Journal of Physics: Conference Series, 1402(6), 066031 https://doi.org/10.1088/1742 6596/1402/6/066031

[36]. Syamsunur, D., Ismail, A., Rahmat, R., \& Karim, O. (2011). Knowledge-based expert system for route selection of road alignment. Australian Journal of Basic and Applied Sciences, 5(5), 208213.

[37]. Tan, C. F., Wahidin, L. S., Khalil, S. N., Tamaldin, N., Hu, J., \& Rauterberg, G. W. M. (2016). The application of expert system: A review of research and applications. ARPN Journal of Engineering and Applied Sciences, 11(4), 2448-2453.

[38]. Tripathi, K.P. (2011). A review on the knowledgebased expert system: Concept and architecture. International Journal of Computer Applications, Special Issue on Artificial Intelligence Techniques Novel Approaches and Practical Applications, 4, 19-23 
Figure 1. Double-Flank Conceptual Measuring (Source: Mustapha, 2017)

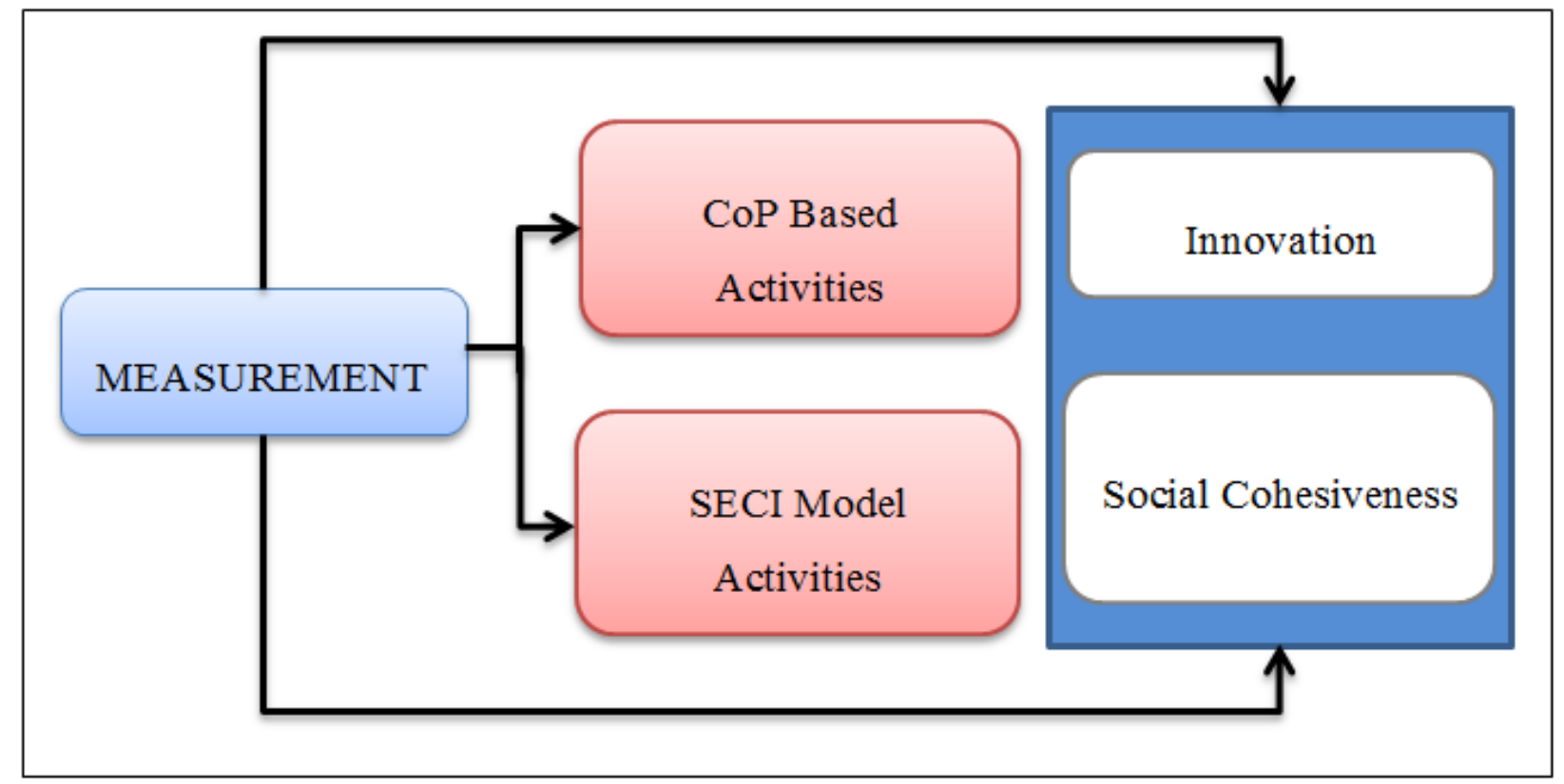

Figure 2 Architecture of the expert system (Source: Sayali Bagwe, 2017)

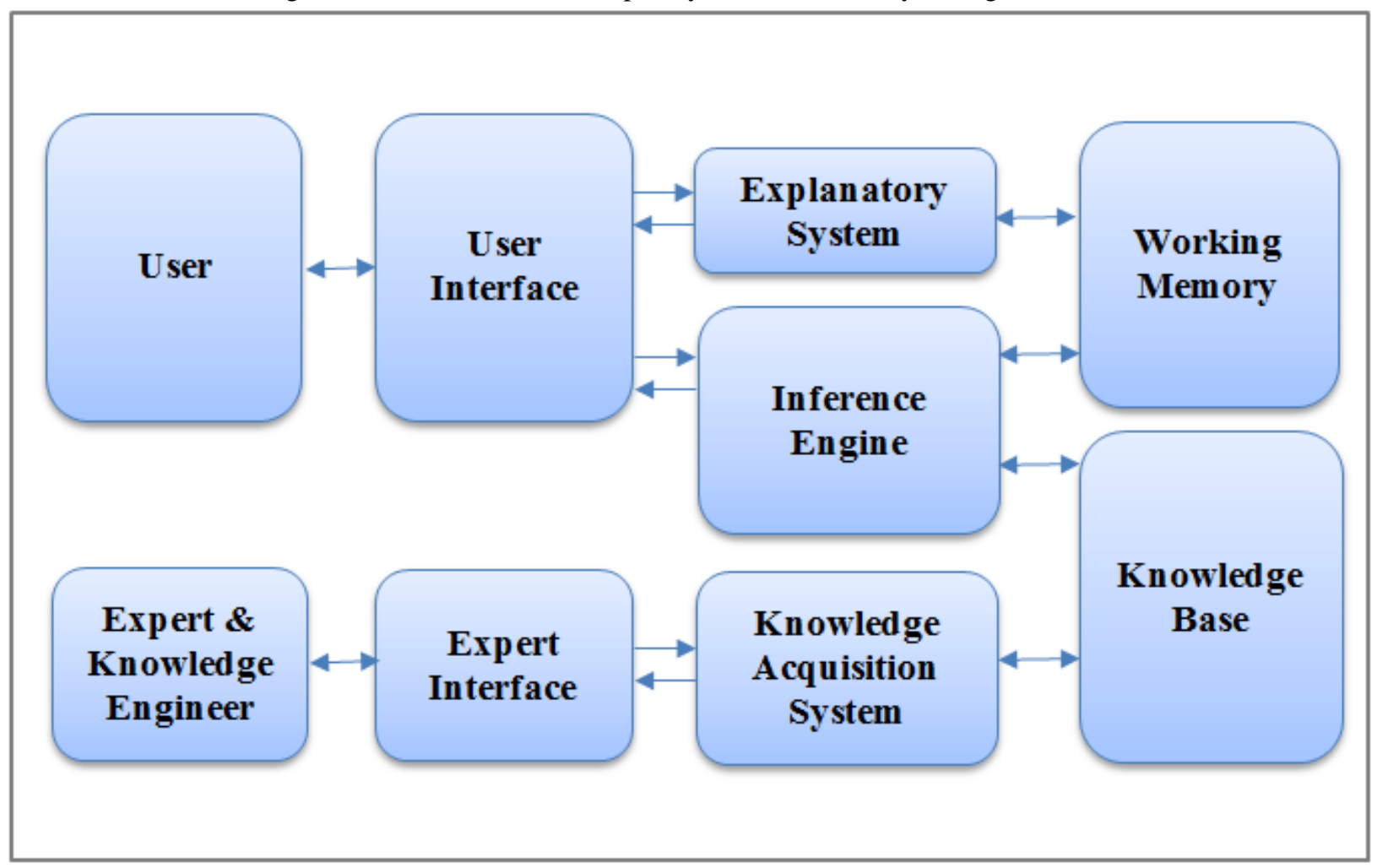


Figure 3 The system ADEPT scheme (Source: Krišová \& Pokorný, 2016)

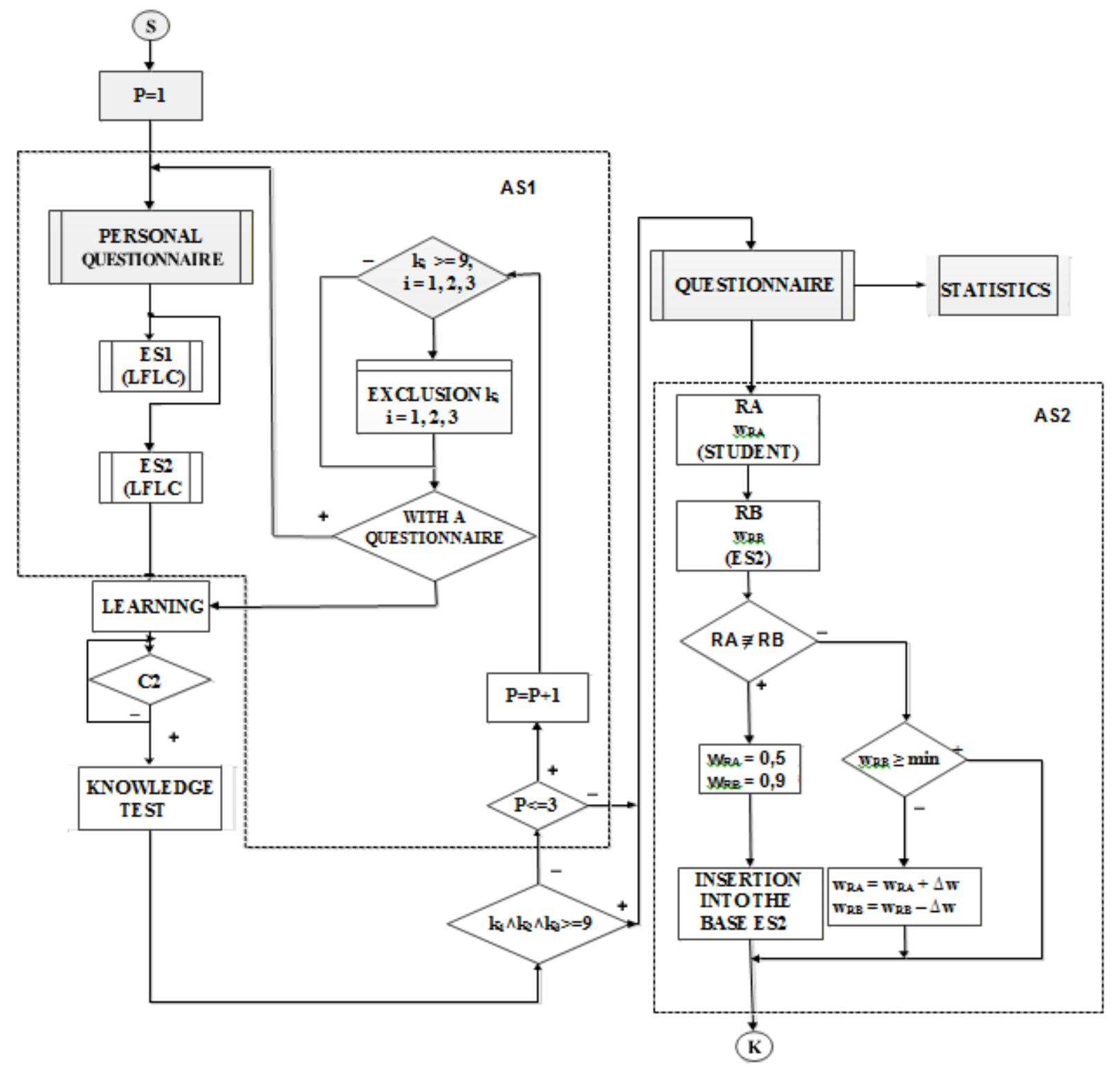

